\title{
Article \\ The Mediating Effect of Dispositional Gratitude on the Relationship between Religious Struggles and Self-Esteem: Preliminary Results
}

\author{
Małgorzata Szcześniak $^{1, *(\mathbb{D})}$, Adam Falewicz ${ }^{1}$ (D), Daria Madej ${ }^{1}$, Grażyna Bielecka ${ }^{1}$, Joanna Pracka ${ }^{1}$ and \\ Radosław Rybarski ${ }^{2}$
}

1 Institute of Psychology, Faculty of Social Sciences, University of Szczecin, 71-017 Szczecin, Poland; adam.falewicz@usz.edu.pl (A.F.); daria.madej77@gmail.com (D.M.); grazynabielecka6@gmail.com (G.B.); joanna.pracka@usz.edu.pl (J.P.)

2 Department of Social Psychology and Psychology of Religion, Institute of Psychology, Faculty of Social Sciences, The John Paul II Catholic University of Lublin, 20-950 Lublin, Poland; radoslaw.rybarski@kul.pl

* Correspondence: malgorzata.szczesniak@usz.edu.pl

check for

updates

Citation: Szcześniak, Małgorzata,

Adam Falewicz, Daria Madej,

Grażyna Bielecka, Joanna Pracka, and Radosław Rybarski. 2022. The Mediating Effect of Dispositional Gratitude on the Relationship between Religious Struggles and Self-Esteem: Preliminary Results. Religions 13: 70. https://doi.org/ 10.3390/rel13010070

Academic Editor: Hans Zollner

Received: 1 November 2021

Accepted: 9 January 2022

Published: 12 January 2022

Publisher's Note: MDPI stays neutral with regard to jurisdictional claims in published maps and institutional affiliations.

Copyright: (C) 2022 by the authors. Licensee MDPI, Basel, Switzerland. This article is an open access article distributed under the terms and conditions of the Creative Commons Attribution (CC BY) license (https:// creativecommons.org/licenses/by/ $4.0 /)$.

\begin{abstract}
In comforting or distressing circumstances, individuals tend to have various perceptions of themselves. It seems that religious comfort and religious distress correlate differently with people's self-esteem. Since the relationship between religiosity and self-esteem is not only direct but can be mediated by other factors that are recognized as buffers against adverse situations, our main goal was to verify whether dispositional gratitude may have an indirect effect on the association between both variables. The research involved data from 254 participants aged 18 to $25(M=21.24$; $S D=2.09)$ and included 192 women $(76 \%)$ and 62 men $(24 \%)$. To measure the title variables, we used: the Religious Comfort and Strain Scale (RCSS), the Rosenberg Self-Esteem Scale (RSES), and the Gratitude Questionnaire (GQ-6). The results showed that people who consider religion as a source of comfort express positive attitudes toward the self and recognize others' kindness, as well. In contrast, people who consider religiosity as a cause of fear, stress, and internal strain tend to display a lower subjective sense of personal worth and lower appreciation of the positivity around them. Moreover, gratitude had a mediatory effect on the relationships between religious comfort/negative emotions toward God and self-esteem.
\end{abstract}

Keywords: religious/spiritual struggles; self-esteem; dispositional gratitude; young Catholics

\section{Introduction}

Religiosity is considered to be a complex phenomenon (Krause 2012) that is related to different dimensions of life. It may provide meaning (Aghababaei and Błachnio 2014), encourage personal growth (Schaefer and Moos 2001), help in overcoming different problems (Newman and Pargament 1990), alleviate the negative effects of stressors (Branco 2001), and enhance well-being (Jackson and Bergeman 2011; Villani et al. 2019). However, religiosity does not always bring relief (Zarzycka and Puchalska-Wasyl 2019). People sometimes experience a lack of positive spiritual feelings (Büssing et al. 2013), undergo religious strains (Szcześniak and Timoszyk-Tomczak 2020), struggle with a spiritual crisis (Büssing et al. 2016), or have a perception of divine disengagement (Exline et al. 2021). In comforting and distressing circumstances, individuals tend to have various ideas about the self.

Based on various studies, we can assume that the relationship between religiosity and self-esteem is not only direct, but can be mediated by other factors, which are recognized as buffers against adverse situations. Given that appreciation of the positive aspects of life and thankfulness have been found to play this role in various studies, we chose dispositional gratitude to verify whether being grateful may have an indirect effect on the association between religious strains and self-esteem among young Catholics. 


\subsection{Religiosity and Self-Esteem}

The concept of self-esteem is omnipresent (Orth and Robins 2014). One way to conceptualize self-esteem is advanced by Rosenberg et al. (1995, p. 141) who considers self-esteem as a "positive or negative attitude toward the self".

According to some researchers (Leary 1999; Andersen et al. 2000; Pyszczynski et al. 2004), self-esteem is as a basic human need and an essential motive for psychological functioning. Other authors maintain that self-esteem may serve as a protecting or buffering mechanism against the effects of challenging experiences (Cast and Burke 2002), emotional distress (Brown 2010), anxiety (Pyszczynski et al. 2004; Sowislo and Orth 2013), and mortalityrelated thoughts (Gailliot et al. 2007). The last conceptualization, widely adopted among psychologists, addresses self-esteem as an outcome of personal achievements and social approval (Leary 2003).

In the present study, we consider self-esteem according to the third perspective, this is, as an output and a possible effect of religious experience. The association between religiosity and self-esteem is somewhat ambivalent or unclear (Markstrom 1999), showing sometimes positive (Smith et al. 1979; Bahr and Martin 1983; Ciarrochi and Heaven 2012; Thompson et al. 2012; Ghorbani et al. 2013; Cheadle et al. 2018; Rooney et al. 2020; Abu-Raiya et al. 2021; Kane et al. 2021), negative (Watson et al. 1985, 1995), or even no (James et al. 2003; Ghaffari and Çiftçi 2010; Aydin et al. 2010) correlations between both phenomena.

Sedikides and Gebauer (2021) explain these conflicting or inconsistent results referring to two different standpoints. Based on the ego-quieting approach, the authors point out that religious people tend to display lower self-esteem because they reduce excessive self-focus and transcend extreme self-interest. Other researchers (Bauer and Wayment 2008; Wayment et al. 2015) suggest that religious principles invite people to exceed egoistic aspirations of the self. Likewise, intrinsic religiosity and spiritual maturity are positively associated with self-esteem and other indicators of mental health (Sanders et al. 2015). However, according to the perspective of the self-centrality principle as universal (Sedikides and Gebauer 2021), religious people are inclined to reveal higher self-esteem in more religious cultures than in less religious countries (Gebauer et al. 2012). Moreover, various religious components or operationalizations of the construct may influence self-esteem differently (Krause 1992; Villani et al. 2019; Gábová et al. 2021).

Empirical research on religiosity and self-esteem largely confirms the theoretical insights proposed by Sedikides and Gebauer (2021) and show compatible results. For example, Szcześniak and Timoszyk-Tomczak (2020) have shown that religious comfort correlated positively with self-esteem, but the dimensions of religious/spiritual struggles, such as fear/guilt, negative emotions toward God, and negative social interactions surrounding religion, showed inverse associations. Other authors (Błażek and Besta 2012), found that religious openness, considered to be a more mature form of religiosity, has been a predictor of self-esteem. Considering the previous outcomes, we hypothesized that:

Hypothesis 1 (H1). Fear/guilt, negative emotions toward God and religious community are negatively correlated with self-esteem. Religious comfort is positively associated with self-esteem.

\subsection{Religiosity and Dispositional Gratitude}

Gratitude has recently raised considerable attention among psychology researchers (Jun et al. 2018; Kong et al. 2021). Gratitude has been mainly conceived as a trait (McCullough et al. 2002, 2004), a mood (McCullough et al. 2004), and an emotion (McCullough et al. 2001, 2002, 2004; Haidt 2003). In its dispositional meaning, which is also considered in the present study, being grateful refers to "a generalized tendency to recognize and respond with grateful emotion to the roles of other people's benevolence in the positive experiences and outcomes that one obtains" (McCullough et al. 2002, p. 112).

Quantitative and qualitative studies of the antecedents and consequences of gratitude (Reckart et al. 2017) have shown that gratitude tends to be associated with personality traits 
(McCullough et al. 2001; Szcześniak et al. 2020a), various dimensions of psychological wellbeing (Wood et al. 2009; Lin 2015a, 2015b; Voci et al. 2019), physical health (Kaczmarek et al. 2015; Krause et al. 2015; Lavelock et al. 2016; O'Connell and Killeen-Byrt 2018; Gallagher et al. 2020), quality of social relationships (Algoe et al. 2008; Layous and Lyubomirsky 2014), and religiosity (Lambert et al. 2009). With respect to the latter correlate, there is some evidence that highly religious people are inclined to be more grateful than their less religious counterparts (Kraus et al. 2015). Several researchers (Sandage et al. 2011; Tulbure 2015; Aghababaei et al. 2018) suggested that internalized religious motivations and engagement may co-occur with grateful thoughts, emotions, and behaviors. In a recent study, Büssing et al. (2021) have indicated that people who have a religious background are more grateful.

Regarding religious/spiritual struggles and gratitude, studies show that experience of negative thoughts and emotions toward the divine or religious community correlates inversely with gratitude. Szcześniak et al. (2019) have noticed that young Roman Catholics who felt fear/guilt of being unforgiven by God, perceived Him as remote or inaccessible, and had aversive emotions related to other believers, simultaneously reported a lower tendency to observe, appreciate and thank for the positive things in life. Similarly, Catholic laypersons who had the impression of their prayers going unanswered, experienced diminished gratitude/awe (Büssing et al. 2020). Based on the research discussed above, we assumed that:

Hypothesis 2 (H2). Fear/guilt, negative emotions toward God, and religious community are negatively correlated with dispositional gratitude. Religious comfort is positively associated with gratitude.

\subsection{Dispositional Gratitude and Self-Esteem}

A large body of research (Rash et al. 2011; Chen and Wu 2014; Kong et al. 2015; Lin 2015a, 2015b; Zhang et al. 2017; Bernardo et al. 2018; Unanue et al. 2019; Bartlett et al. 2020) has shown that gratitude correlates with or positively predicts self-esteem. Likewise, experimental studies (Rash et al. 2011) have proved that 4 weeks of grateful contemplation increased participants' levels of self-esteem.

Gratitude has been found to enable beneficiaries to undertake altruistic behaviors intended to reciprocate the benefactor (Yue et al. 2017; Preś et al. 2020), engage in prosocial actions toward "third" others through upstream reciprocity (Bartlett and DeSteno 2006; Chang et al. 2012; Szcześniak 2018), and nourish interpersonal relationships (Balconi and Fronda 2021). Besides having social effects, gratitude is believed to provide psychological benefits (Bono and Sender 2018), make recipients enjoy positive experiences (Grant and Gino 2010), and affect their personal confidence. These findings are in line with Fredrickson's broadenand-build theory, which suggests that gratitude, like other positive emotions, may bolster a more secure identity (Park et al. 2021), and develop or strengthen lasting personal resources (Lin 2015a, 2015b; Burzynska and Stolarski 2020). Receiving something valuable or good from someone else and recognizing others' commitment to one's own benefit (Mesurado et al. 2021) may promote self-esteem. Based on the research discussed above, we assumed that:

Hypothesis 3 (H3). Dispositional gratitude is positively correlated with self-esteem.

\subsection{Dispositional Gratitude as a Mediator}

The direct relationship between religiosity and self-esteem is very well documented. However, Krause (1992) has recommended moving beyond the linear association between religiosity and different dimensions of well-being to identify potential mechanisms that may bond both phenomena. As outlined earlier, religious comfort and dimensions of religious/spiritual struggle may be linked to self-esteem via dispositional gratitude since gratitude is adaptive in human functioning (Bono and Sender 2018) and makes people 
feel good (Ryan 2007). The theoretical and empirical rationale behind choosing gratitude concerns its buffering and bolstering capacity of lowering anxiety and increasing people's resilience (Waters et al. 2021). Gratitude has been viewed as one of the most beneficial emotions that helps people to deal with difficult situations (Krause 2006), find meaning in life (Bono and Sender 2018), and restructure the relationship with the self (Homan and Hosack 2019).

According to the amplification theory of gratitude proposed by Watkins (2014a, 2014b), gratitude increases the good in people's lives, enhances coping abilities, and empowers them to perceive difficult events from a different perspective, to see beyond stressful events, and to act despite adversities (Fredrickson et al. 2003). Moreover, empirical evidence (Homan and Hosack 2019) has shown that grateful people are inclined to reinforce their self-worth in intrinsic domains. Therefore, it is plausible that "counting blessings", regardless of pain, tension or confusion related to religious or spirituals domains of life (Magyar-Russell 2021), may strengthen peoples' self-esteem. Drawing on the conceptual premises presented above, we hypothesized that:

Hypothesis 4 (H4). Dispositional gratitude mediates the relationship between dimensions of religious/spiritual struggle and self-esteem.

\section{Materials and Methods}

\subsection{Participants and Procedure}

Our research involved the data gained from 254 participants between 18 and 25 $(M=21.24 ; S D=2.09)$, and included 192 women $(76 \%)$ and 62 men $(24 \%)$. The study was conducted with the participation of young Polish Catholics who completed the online survey. The link to the battery of questionnaires was distributed primarily through different online religious groups on Facebook, and discussion groups such as "Spirituality" or "Jesus-way of life". The respondents were asked to indicate how much they considered themselves as engaged in their faith. Almost 35\% declared they were not involved at all, $29 \%$ - slightly, $27 \%$-average, and $9 \%$ - highly. These numbers denote that the group of Catholics was very diverse. Although most participants expressed lower commitment to their religious beliefs, they were included in the analysis since they openly declared being Catholics. This choice was dictated by the fact that living out one's faith is similar to a continuum on which there can be both people who are very faithful and committed, and people who honestly confess that they have a problem with their faith. In this sense, being a "lost" or "seeking" Catholic does not mean that one is an atheist.

Another criterion of participation was the age between 18 and 25 years of age. This choice was because young people graduating from high school, starting university, and entering adulthood, which is an opportunity for many of them to gain their own experience of faith without the direct influence of parents or church community. This developmental stage of life may be time both of doubts, fears, or negative emotions towards God or Catholic institutions, and of an increase in self-esteem (Erol and Orth 2011).

\subsection{Religious Comfort and Strain Scale}

The Religious Comfort and Strain Scale (RCSS), developed by Exline et al. (2000) and adapted into Polish by Zarzycka (2014), measures the comforting experience of religion/spirituality (one subscale) and awareness of religious/spiritual strain (three subscales). Religious comfort applies to the feeling of being loved by God (Abernethy et al. 2020) and having a sense of belonging to a religious community (e.g., "Trust God to protect and care for you"). The fear/guilt subscale reflects preoccupations about one's own wrongdoings and the doubts that arise from them about God's lack of forgiveness (e.g., "Believe that God sees you as a bad person"). Negative emotions toward God refer to feelings of being abandoned and punished by God (e.g., "Feel angry at God"). Negative social interactions surrounding religion includes negative feelings associated with the family, clergy, and religious community (e.g., "Feel resentment toward others in your religious group"). The 
RCSS is a 28-item scale. The participants rate each item by using multiple-choice answers on an 11-point Likert scale that ranges from $0=$ not at all to $10=$ extremely. In the current study, the Cronbach's alphas presented very good values: religious comfort with $\alpha=0.97$, fear/guilt with $\alpha=0.79$, negative emotions toward God with $\alpha=0.84$, and negative social interactions surrounding religion with $\alpha=0.76$.

\subsection{Rosenberg Self-Esteem Scale}

The Rosenberg Self-Esteem Scale (RSES), authored by Rosenberg (1965) and adapted into Polish by Łaguna et al. (2007), assesses people's set of thoughts and feelings about their own worth and importance. It is a 10-item scale that has 5 positively (e.g., "On the whole, I am satisfied with myself") and 5 negatively (e.g., "At times I think I am no good at all") worded statements about one's own self-esteem. Respondents rate their level of agreement by using a 4-point Likert scale (from 1 = strongly agree to $4=$ strongly disagree). The total score ranges from a minimum of 10 to a maximum of 40 points. The higher the final score, the higher the self-esteem. It is valuable to notice that the average value of self-esteem in the present group $(M=2.82 ; S D=0.57)$ was at the similar level as in other studies involving young adults. For example, Błachnio et al. (2016) reported that young people $(M=21.63$, $S D=2.62)$ had self-esteem equal to $M=2.98(S D=0.50)$. Eaguna et al. (2007) found that self-esteem among students was $M=2.94(S D=4.16)$. The Cronbach's alpha reliability coefficients of the original English version of the questionnaire was 0.86 . In the adapted Polish version, in different age groups, Cronbach's alpha oscillated between 0.81 and 0.83 (Eaguna et al. 2007). In the present study, the value of $\alpha$ was equal to 0.86 .

\subsection{Gratitude Questionnaire}

The Gratitude Questionnaire (GQ-6), originated by McCullough et al. (2002) and adapted into Polish by Kossakowska and Kwiatek (2014), is a short 6-item questionnaire that measures self-report disposition to experience gratitude (e.g., "I have so much in life to be thankful for"). The respondents evaluate each statement by using multiple-choice answers on a 7-point Likert scale that ranges from $1=$ strongly disagree to $7=$ strongly agree. Two items (3 and 6) are reverse scored (e.g., "When I look at the world, I don't see much to be grateful for"). The higher the final result, the higher level of dispositional gratitude. Different studies report a good coefficient alpha of 0.82 for original English version of questionnaire (McCullough et al. 2002). In the adapted Polish version, Cronbach's alpha was 0.71 (Kossakowska and Kwiatek 2014). In the present study, the value of $\alpha$ was equal to 0.67 .

\subsection{Statistical Analysis}

The statistical analysis was performed using the Statistical Package for the Social Sciences (SPSS software version 20, IBM, Armonk, NY, USA). Data normality was checked by computing the coefficients of skewness and kurtosis. Descriptive statistics and Pearson's correlations were calculated to analyze the associations between religious comfort and the three dimensions of religious/spiritual struggles, self-esteem, and dispositional gratitude.

A linear regression model was run to (1) verify the degree of multicollinearity, (2) find outliers, and (3) control for suspected confounders in the relationship between religious/spiritual struggles and self-esteem: sex, age, and faith engagement. For the first goal, we used an index of tolerance less than 0.2 and variance inflation factors (VIFs) higher than 5.0 as indicatives of high intercorrelations (Światek et al. 2021). For the second aim, we used the value of Mahalanobis' distance not being lower than $p=0.001$ and the value of Cook's distance not being higher than 1 (Szcześniak and Strochalska 2021). To realize the third objective, we chose the variables of sex, age, and religious engagement. In fact, previous research has consistently found that women tend to be more religious (Feltey and Poloma 1991; Collett and Lizardo 2009) and grateful (Kashdan et al. 2009; Guse et al. 2019). Simultaneously, several studies (Kling et al. 1999; Gentile et al. 2009; Bleidorn et al. 2016; Zeigler-Hill and Myers 2012) have found that men score higher than women on 
both the general and specific domains of self-esteem across their life span, even though the difference is small. Interestingly, all of the above-mentioned variables also vary with respect to age. The literature has shown that young people tend to declare lower levels of religiosity (Argue et al. 1999), gratitude (Chopik et al. 2019), and self-esteem (Erol and Orth 2011).

The PROCESS macro (version 3.2) (Hayes 2013), with 95\% bias-corrected bootstrap confidence intervals, and a 5000 resampling analysis was adopted to compute dispositional gratitude's role in the relationship between religious comfort/negative dimensions of religious struggle and self-esteem.

\section{Results}

\subsection{Preliminary Analyses}

Religious comfort, the three dimensions of religious struggle (fear/guilt, negative emotions toward God, and negative emotions toward religious community), self-esteem, and dispositional gratitude were tested for normality using skewness and kurtosis. The values of the analyzed variables were between \pm 2 , indicating a near normal distribution (Table 1).

Table 1. Descriptive statistics for Religious Comfort and Strain Scale, Rosenberg Self-Esteem Scale, Gratitude Questionnaire $(N=254)$.

\begin{tabular}{ccccc}
\hline Scales & M & SD & Skewness & Kurtosis \\
\hline Religious comfort & 5.35 & 2.84 & 0.11 & -1.24 \\
Fear/guilt & 3.43 & 1.73 & 0.69 & 0.10 \\
Negative emotions God & 2.61 & 1.69 & 1.24 & 0.93 \\
Negative emotions people & 4.36 & 1.77 & 0.53 & -0.03 \\
Self-Esteem & 2.82 & 0.57 & -0.18 & -0.44 \\
Dispositional Gratitude & 30.75 & 5.38 & -0.45 & 0.55 \\
\hline
\end{tabular}

\subsection{Correlations}

The results (Table 2) indicate statistically significant positive associations between: (1) religious comfort, self-esteem, and dispositional gratitude; and (2) dispositional gratitude and self-esteem. Negative correlations were found between: (3) fear/guilt and self-esteem; (4) negative emotions toward God, self-esteem, and dispositional gratitude; and (5) negative emotions toward people/institutions related to religion and self-esteem.

Table 2. Pearson's correlation results for all measured variables.

\begin{tabular}{|c|c|c|c|c|c|c|}
\hline Scales & RC & FG & NEG & NEC & SE & DG \\
\hline Religious comfort (RC) & 1 & $0.34^{* * *}$ & $-0.38^{* * *}$ & $-0.23^{* * *}$ & $0.21 * * *$ & $0.43^{* * *}$ \\
\hline Fear/guilt (FG) & & 1 & $0.21 * * *$ & $0.11^{\mathrm{t}}$ & $-0.24^{* * *}$ & 0.09 \\
\hline Negative emotions God (NEG) & & & 1 & $0.28 * * *$ & $-0.41^{* * *}$ & $-0.31 * * *$ \\
\hline Negative emotions people (NEP) & & & & 1 & $-0.13 *$ & -0.09 \\
\hline Self-Esteem (SE) & & & & & 1 & $0.34^{* * *}$ \\
\hline Dispositional Gratitude (DG) & & & & & & 1 \\
\hline
\end{tabular}

The outcomes confirmed hypotheses H1 and H3, showing statistically significant associations between all of the dimensions of the RCSS and self-esteem (H1), and selfesteem and gratitude (H3). Moreover, hypothesis $\mathrm{H} 2$ was partially corroborated, since only two dimensions of the RCSS were associated with dispositional gratitude. It can be assumed that people who declare that religion is for them a source of comfort, express positive attitudes toward the self and recognize others' kindness, as well. In contrast, people who consider religiosity as a cause of internal strain tend to display a lower subjective sense of personal worth and a lower appreciation of the positive around them. 


\subsection{Multicollinearity and Confounding Variables}

The outcomes of the multiple linear regression indicate that there was not a problem with high correlations between the independent variables and no evidence of multicollinearity. Although the Mahalanobis' distance indicated the presence of two influential cases, the problematic outliers were not removed since the correlational statistics with and without their presence were comparable. Moreover, the VIF values were between 1.01 and 3.27, and the tolerance values were between 0.80 and 0.98 , showing no indices for concern. Cook's values did not surpass 1 and were in the acceptable range of between 0.000 and 0.097 . The results revealed that the participants' sex, age, and their engagement in faith were not a set of confounding factors. They accounted for a small $4.2 \%$ of the variance $\left(R^{2}=0.042\right)$ with the following values for $\operatorname{sex}(\beta=0.084 ; \mathrm{t}=1.499 ; p=0.135)$, age $(\beta=0.105 ; \mathrm{t}=1.914$; $p=0.057)$, and faith engagement $(\beta=0.033 ; \mathrm{t}=0.379 ; p=0.705)$. All of the predictors explained a further $23 \%$ of the variance.

\subsection{Mediational Models}

Next, we performed a mediation analysis in PROCESS (Hayes 2013). As Table 3 demonstrates, dispositional gratitude acted as a mediator in the models RC-DG-SE and NEG-DG-SE. The dimensions of fear/guilt and negative emotions toward religious community were not included in the models since they did not meet the required condition of significant correlations with the independent/dependent variables. In both cases, the 95\% bootstrap confidence intervals did not include zero, and the $c^{\prime}$ paths were reduced compared with the $\mathrm{c}$ paths after adding dispositional gratitude.

Table 3. Role of Dispositional gratitude in the relationship between Religious comfort/Negative emotions toward God and Self-Esteem $(N=254)$.

\begin{tabular}{ccccccc}
\hline Scales & a Path & \multirow{2}{*}{ b Path } & c Path & c' Path & $\begin{array}{c}\text { Indirect Effect } \\
\text { and B (SE) }\end{array}$ & $\begin{array}{c}\text { 95\% CI LOWER } \\
\text { UPPER }\end{array}$ \\
\hline RC-DG-SE & $0.80^{* * *}$ & $0.03^{* * *}$ & $0.04^{* * *}$ & $0.01(\mathrm{~ns})$ & $0.0263(0.0067)$ & $0.0136 ; 0.0404$ \\
NEG-DG_SE & $-0.98^{* * *}$ & $0.02^{* * *}$ & $-0.14^{* * *}$ & $-0.11^{* * *}$ & $-0.0247(0.0089)$ & $-0.0440 ;-0.0093$ \\
\hline
\end{tabular}

*** $p<0.001$; ns-not significant; RC-Religious comfort; NEG-Negative emotions toward God; DGDispositional gratitude; SE-Self-Esteem; a path—effect of the RC/NEG on the DG; b path-effect of the DG on the SE; c path-effect of the RC/NEG on the SE; $c^{\prime}$ path—direct effect of the RC/NEG on the SE while controlling for the DG.

\section{Discussion}

In terms of H1, fear/guilt, and negative emotions toward God and toward religious community/institution negatively correlated with self-esteem. Religious comfort, as a positive dimension of religiosity, was positively associated with self-esteem. These outcomes confirm our hypothesis and are in line with the previous studies. For example, Reiland and Lauterbach (2008) and Ghafoor et al. (2018) have found that religiosity may act as a potential protector against human suffering. This seems to be the case especially when people have a positive conception of the divine (Schieman et al. 2017) and are religiously committed (Ellison 1993; Krause 1992, 1995; Markstrom 1999; Hill et al. 2008). In the first condition, if individuals hold beliefs that God is a loving, caring, and accepting figure, they tend to declare higher self-esteem (Benson and Spilka 1973; Greenway et al. 2003; Joshanloo and Daemi 2015; Grubbs et al. 2016) and self-worth (Francis et al. 2001). In fact, Krause (1992) has suggested that religiosity affects feelings of the internal sense of one's own value. In other words, self-esteem may be related to the nature of beliefs about God (Schieman et al. 2017). Belonging to a religious community in which people find understanding and support is not without significance for the self-esteem of its members (Smith and Crosby 2017), as well. Positive feedback from fellow believers may be positively associated with self-esteem. Moreover, Grubbs et al. (2016) have observed that experience of religious struggle, in its different forms (divine, demonic, interpersonal, moral, ultimate meaning, and doubt) is related to low self-esteem. Grubbs et al. (2016) have reported that 
negative attributions of God's intent, lack of meaning found in the struggle, and decline in response to religious or spiritual strain correlated negatively with self-esteem.

With respect to $\mathrm{H} 2$, gratitude positively correlated with religious comfort and inversely with negative emotions toward God. However, fear/guilt and negative emotions religious community did not correlate with dispositional gratitude. The obtained outcomes partially corroborate our assumptions and several previous findings ( $\mathrm{Ng}$ and Chan 2015; Szcześniak et al. 2019; Loi and Ng 2021). Given that gratitude is mentioned and promoted in religious texts ( $\mathrm{Ng}$ and Chan 2015; Loi and Ng 2021), and can coexist with religious faith (Homan et al. 2014), it is understandable that the positive experience of gratitude is positively associated with the feeling of being loved by God. Moreover, based on their experimental study, Lambert et al. (2009) have concluded that people who prayed daily to God declared higher levels of gratitude than those who were not praying. Krause et al. (2015) have confirmed that having a benevolent image of God resulted in higher gratitude. In contrast, divine struggles experienced in the form of being distant from God may co-occur with lower gratitude in accordance with the principle that in times of crisis or suffering people usually experience more negative emotions. In fact, people who are dealing with religious strains usually tend to report more anger toward God (Exline and Bright 2011) and less gratitude (Szcześniak et al. 2019).

Regarding H3, dispositional gratitude was positively correlated with self-esteem, which is in line with some theories and other previous studies. According to the sociometer approach, people with high self-esteem are aware that they are valued by others, and those who have low self-esteem doubt whether they are considered worthwhile (Anthony et al. 2007). In this regard, Leary (1999) has clarified that self-esteem is greatly influenced by circumstances that affect the degree to which individuals are respected by other people. Thus, higher self-esteem may be connected to others' approval, kindness, inclusion, understanding, or appreciation. According to McCullough et al. (2002), people who see themselves as the beneficiaries of other people's kindness and benevolence may feel more esteemed. When people perceive that someone else cares for them or supports their efforts, they may feel more self-respect (Emmons and Mishra 2011). In turn, Petrocchi and Couyoumdjian (2016) have specified that dispositional gratitude correlates negatively with feelings of inadequacy or self-repugnance and is positively associated with the ability to treat the self with kindness. Thus, lower self-esteem may stem from others' disapproval, devaluation, exclusion, abandonment, or refusal which have negative consequences for relational appraisal.

Finally, referring to $\mathrm{H} 4$, gratitude had a mediatory effect on the relationships between religious comfort/negative emotions toward God and self-esteem. Based on the outcomes gained in the present study, it can be implied that religiosity, considered as a source of sense and empowerment (Fiori et al. 2006; Szcześniak et al. 2020b), may be associated with people's own feelings of worthiness when they recognize others' good actions, appreciate their gifts or gestures, and respond positively to obtained benefits (Sansone and Sansone 2010). This is possible because gratitude is "intrinsically self-esteeming" (Emmons 2004, p. 5) and generally makes people feel good. A mediational role of gratitude can also be noticed in the experience of religious/spiritual struggles. In this case, despite various religious or spiritual difficulties, people may still elevate their self-esteem given that gratitude buffers against unpleasant states and external or internal adversities (Kane et al. 2021). In fact, Algoe and Zhaoyang (2016) have confirmed through experimental analyses that gratitude, besides yielding interpersonal advantages, provides intrapersonal benefits, as well. It is plausible to assume that the feeling of being respected by others, and thus experiencing gratitude, builds several psychological resources (Algoe and Zhaoyang 2016) that can be used in hard times of religious doubts or strains and boost self-esteem. Previous literature has shown that gratitude, in its role of mediator, may lead to a considerable decrease in stress (Wood et al. 2008; Cheng et al. 2015; O'Connell and Killeen-Byrt 2018), and can act as a buffer against anxiety (Rosmarin et al. 2010; Stoeckel et al. 2015), negative emotions 
(Fredrickson et al. 2000), loneliness (O'Connell and Killeen-Byrt 2018), and psychological distress (Wong et al. 2017).

\section{Limitations}

This study is not free from some shortcomings. The first limitation relates to the mediational nature of the current study, which prevents causal inferences between the variables considered. In the future, the use of a design that allows the existence of a temporary sequence between variables would be an appropriate solution. Another limitation consists in the lack of proportion between the number of women and men in the research group, which makes it impossible to generalize the results. Almost three to one ratio of females over males observed in the current study reflects the existing tendency of female outnumbering males in willingness to participate in different data collection (Severiens and Dam 2011). In subsequent studies, it would be important to ensure a similar number of women and men.

\section{Conclusions}

The results obtained in the present study suggest that a positive (religious comfort) and challenging (religious struggle in the form of negative emotions toward God) experience of religiosity may not be indifferent to individuals' attitudes toward the self through the tendency to perceive and value positive aspects of life. When people find meaning and security in religion, they may evaluate themselves more positively, seeing around them benefits deriving from others. In this sense, dispositional gratitude serves as an incentive to evaluate one's own worth or importance. Instead, when religion begins to be a source of struggle or suffering, a perception of people's benevolence may act as a buffer against the negative spiritual experience, and even in these circumstances people can maintain a sense of self-worth.

Author Contributions: Conceptualization, M.S., A.F., D.M. and G.B.; Formal analysis, A.F.; Investigation, M.S., A.F., D.M., G.B. and J.P.; Methodology, M.S., A.F., D.M., G.B. and R.R.; Resources, M.S., A.F., D.M., G.B., J.P. and R.R.; Supervision, M.S.; Writing—original draft, M.S., A.F., D.M., G.B., J.P. and R.R. All authors have read and agreed to the published version of the manuscript.

Funding: This research received no external funding.

Institutional Review Board Statement: The study was conducted according to the guidelines of the Declaration of Helsinki and approved by the Bioethics Committee of the Institute of Psychology at the University of Szczecin (protocol code, KB 10/2018).

Informed Consent Statement: Informed consent was obtained from all participants involved in the study.

Data Availability Statement: The data that support the findings of this study are available from the corresponding author, M.S., upon reasonable request.

Conflicts of Interest: The authors declare no conflict of interest.

\section{References}

Abernethy, Alexis D., Joseph M. Currier, Charlotte vanOyen Witvliet, Sarah A. Schnitker, Katharine M. Putman, Lindsey M. Root Luna, Joshua D. Foster, Andrene Spencer, Heather Jones, Karl VanHarn, and et al. 2020. Understanding the Roles of Religious Comfort and Strain on Depressive Symptoms in an Inpatient Psychiatric Setting. Psychology of Religion and Spirituality 12: 366-75. [CrossRef]

Abu-Raiya, Hisham, Tali Sasson, and Rebecca Alma Cohen. 2021. Is Religiousness a Unique Predictor of Self-Esteem? An Empirical Investigation with a Diverse Israeli Sample. Psychology of Religion and Spirituality. [CrossRef]

Aghababaei, Naser, and Agata Błachnio. 2014. Purpose in Life Mediates the Relationship between Religiosity and Happiness: Evidence from Poland. Mental Health, Religion \& Culture 17: 827-31. [CrossRef]

Aghababaei, Naser, Agata Błachnio, and Masoume Aminikhoo. 2018. The Relations of Gratitude to Religiosity, Well-Being, and Personality. Mental Health, Religion \& Culture 21: 408-17. [CrossRef]

Algoe, Sara B., and Ruixue Zhaoyang. 2016. Positive Psychology in Context: Effects of Expressing Gratitude in Ongoing Relationships Depend on Perceptions of Enactor Responsiveness. The Journal of Positive Psychology 11: 399-415. [CrossRef] [PubMed] 
Algoe, Sara B., Jonathan Haidt, and Shelly L. Gable. 2008. Beyond Reciprocity: Gratitude and Relationships in Everyday Life. Emotion 8: 425-29. [CrossRef] [PubMed]

Andersen, Susan M., Serena Chen, and Christina Carter. 2000. Fundamental Human Needs: Making Social Cognition Relevant. Psychological Inquiry 11: 269-75. [CrossRef]

Anthony, Danu B., Joanne V. Wood, and John G. Holmes. 2007. Testing Sociometer Theory: Self-Esteem and the Importance of Acceptance for Social Decision-Making. Journal of Experimental Social Psychology 43: 425-32. [CrossRef]

Argue, Amy, David R. Johnson, and Lynn K. White. 1999. Age and Religiosity: Evidence from a Three-Wave Panel Analysis. Journal for the Scientific Study of Religion 38: 423-35. [CrossRef]

Aydin, Nilüfer, Peter Fischer, and Dieter Frey. 2010. Turning to God in the Face of Ostracism: Effects of Social Exclusion on Religiousness. Personality and Social Psychology Bulletin 36: 742-53. [CrossRef]

Bahr, Howard M., and Thomas K. Martin. 1983. And Thy Neighbor as Thyself': Self-Esteem and Faith in People as Correlates of Religiosity and Family Solidarity among Middletown High School Students. Journal for the Scientific Study of Religion 22: 132-44. [CrossRef]

Balconi, Michela, and Giulia Fronda. 2021. Gratitude Affects Inter-Subjective Synchronicity for Cognitive Performance and Autonomic Responsiveness. Frontiers in Psychology 12: 1-9. [CrossRef]

Bartlett, Monica, and David DeSteno. 2006. Gratitude and Prosocial Behavior Helping When It Costs You. Psychological Science 17: 319-25. [CrossRef] [PubMed]

Bartlett, Monica Y., Piercarlo Valdesolo, and Sarah N. Arpin. 2020. The Paradox of Power: The Relationship between Self-Esteem and Gratitude. The Journal of Social Psychology 160: 27-38. [CrossRef] [PubMed]

Bauer, Jack J., and Heidi A. Wayment. 2008. The Psychology of the Quiet Ego. In Transcending Self-Interest: Psychological Explorations of the Quiet Ego. Edited by Heidi A. Wayment and Jack J. Bauer. Washington, DC: American Psychological Association, pp. 7-19. [CrossRef]

Benson, Peter, and Bernard Spilka. 1973. God Image as a Function of Self-Esteem and Locus of Control. Journal for the Scientific Study of Religion 12: 297-310. [CrossRef]

Bernardo, Allan B. I., Roseann Tan-Mansukhani, and Mary Angeline A. Daganzo. 2018. Associations Between Materialism, Gratitude, and Well-Being in Children of Overseas Filipino Workers. Europe's Journal of Psychology 14: 581-98. [CrossRef] [PubMed]

Błachnio, Agata, Aneta Przepiórka, and Patrycja Rudnicka. 2016. Narcissism and Self-Esteem as Predictors of Dimensions of Facebook Use. Personality and Individual Differences 90: 296-301. [CrossRef]

Błażek, Magdalena, and Tomasz Besta. 2012. Self-Concept Clarity and Religious Orientations: Prediction of Purpose in Life and Self-Esteem. Journal of Religion and Health 51: 947-60. [CrossRef] [PubMed]

Bleidorn, Wiebke, Ruben C. Arslan, Jaap J. A. Denissen, Peter J. Rentfrow, Jochen E. Gebauer, Jeff Potter, and Samuel D. Gosling. 2016. Age and Gender Differences in Self-Esteem-A Cross-Cultural Window. Journal of Personality and Social Psychology 111: 396-410. [CrossRef] [PubMed]

Bono, Giacomo, and Jason T. Sender. 2018. How Gratitude Connects Humans to the Best in Themselves and in Others. Research in Human Development 15: 224-37. [CrossRef]

Branco, Kenneth J. 2001. Religiosity and Depression Among Nursing Home Residents: Results of a Survey of Ten States. Journal of Religious Gerontology 12: 43-61. [CrossRef]

Brown, Jonathon D. 2010. High Self-Esteem Buffers Negative Feedback: Once More with Feeling. Cognition and Emotion 24: 1389-404. [CrossRef]

Burzynska, Bozena, and Maciej Stolarski. 2020. Rethinking the Relationships Between Time Perspectives and Well-Being: Four Hypothetical Models Conceptualizing the Dynamic Interplay Between Temporal Framing and Mechanisms Boosting Mental Well-Being. Frontiers in Psychology 11: 1033. [CrossRef] [PubMed]

Büssing, Arndt, Andreas Günther, Klaus Baumann, Eckhard Frick, and Christoph Jacobs. 2013. Spiritual Dryness as a Measure of a Specific Spiritual Crisis in Catholic Priests: Associations with Symptoms of Burnout and Distress. Evidence-Based Complementary and Alternative Medicine 2013: 246797. [CrossRef]

Büssing, Arndt, Daniela Rodrigues Recchia, Thomas Dienberg, Janusz Surzykiewicz, and Klaus Baumann. 2021. Awe/Gratitude as an Experiential Aspect of Spirituality and Its Association to Perceived Positive Changes During the COVID-19 Pandemic. Frontiers in Psychiatry 12: 385. [CrossRef]

Büssing, Arndt, Eckhard Frick, Christoph Jacobs, and Klaus Baumann. 2016. Spiritual Dryness in Non-Ordained Catholic Pastoral Workers. Religions 7: 141. [CrossRef]

Büssing, Arndt, Stephan Winter, and Klaus Baumann. 2020. Perception of Religious Brothers and Sisters and Lay Persons That Prayers Go Unanswered Is a Matter of Perceived Distance from God. Religions 11: 178. [CrossRef]

Cast, Alicia D., and Peter J. Burke. 2002. A Theory of Self-Esteem. Social Forces 80: 1041-68. [CrossRef]

Chang, Yen-Ping, Yi-Cheng Lin, and Lung Hung Chen. 2012. Pay It Forward: Gratitude in Social Networks. Journal of Happiness Studies 13: 761-81. [CrossRef]

Cheadle, A. C. D., C. Dunkel Schetter, and Community Child Health Network (CCHN). 2018. Mastery, Self-Esteem, and Optimism Mediate the Link between Religiousness and Spirituality and Postpartum Depression. Journal of Behavioral Medicine 41: 711-21. [CrossRef] [PubMed] 
Chen, Lung Hung, and Chia-Huei Wu. 2014. Gratitude Enhances Change in Athletes' Self-Esteem: The Moderating Role of Trust in Coach. Journal of Applied Sport Psychology 26: 349-62. [CrossRef]

Cheng, Sheung-Tak, Pui Ki Tsui, and John H. M. Lam. 2015. Improving Mental Health in Health Care Practitioners: Randomized Controlled Trial of a Gratitude Intervention. Journal of Consulting and Clinical Psychology 83: 177-86. [CrossRef] [PubMed]

Chopik, William J., Nicky J. Newton, Lindsay H. Ryan, Todd B. Kashdan, and Aaron J. Jarden. 2019. Gratitude across the Life Span: Age Differences and Links to Subjective Well-Being. The Journal of Positive Psychology 14: 292-302. [CrossRef] [PubMed]

Ciarrochi, Joseph, and Patrick C. L. Heaven. 2012. Religious Values and the Development of Trait Hope and Self-Esteem in Adolescents. Journal for the Scientific Study of Religion 51: 676-88. [CrossRef]

Collett, Jessica L., and Omar Lizardo. 2009. A Power-Control Theory of Gender and Religiosity. Journal for the Scientific Study of Religion 48: 213-31. [CrossRef]

Ellison, Christopher G. 1993. Religious Involvement and Self-Perception among Black Americans. Social Forces 71: 1027-55. [CrossRef]

Emmons, Robert A. 2004. The Psychology of Gratitude: An Introduction. Edited by Robert A. Emmons. The Psychology of Gratitude Series in Affective Science. New York: Oxford University Press, pp. 5-16.

Emmons, Robert A., and Anjali Mishra. 2011. Why Gratitude Enhances Well-Being: What We Know, What We Need to Know. In Designing Positive Psychology: Taking Stock and Moving Forward. Edited by Kennon M. Sheldon, Todd B. Kashdan and Michael F. Steger. Series in Positive Psychology; New York: Oxford University Press, pp. 248-62. [CrossRef]

Erol, Ruth Yasemin, and Ulrich Orth. 2011. Self-Esteem Development from Age 14 to 30 Years: A Longitudinal Study. Journal of Personality and Social Psychology 101: 607-19. [CrossRef]

Exline, Julie J., and David S. Bright. 2011. Spiritual and Religious Struggles in the Workplace. Journal of Management, Spirituality E Religion 8: 123-42. [CrossRef]

Exline, Julie J., Joshua A. Wilt, Valencia A. Harriott, Kenneth I. Pargament, and Todd W. Hall. 2021. Is God Listening to My Prayers? Initial Validation of a Brief Measure of Perceived Divine Engagement and Disengagement in Response to Prayer. Religions 12: 80. [CrossRef]

Exline, Julie Juola, Ann Marie Yali, and William C. Sanderson. 2000. Guilt, Discord, and Alienation: The Role of Religious Strain in Depression and Suicidality. Journal of Clinical Psychology 56: 1481-96. [CrossRef]

Feltey, Kathryn M., and Margaret M. Poloma. 1991. From Sex Differences to Gender Role Beliefs: Exploring Effects on Six Dimensions of Religiosity. Sex Roles 25: 181-93. [CrossRef]

Fiori, Katherine L., Edna E. Brown, Kai S. Cortina, and Toni C. Antonucci. 2006. Locus of Control as a Mediator of the Relationship between Religiosity and Life Satisfaction: Age, Race, and Gender Differences. Mental Health, Religion E Culture 9: 239-63. [CrossRef]

Francis, Leslie J., Harry M. Gibson, and Mandy Robbins. 2001. God Images and Self-Worth among Adolescents in Scotland. Mental Health, Religion \& Culture 4: 103-8. [CrossRef]

Fredrickson, Barbara L., Michele M. Tugade, Christian E. Waugh, and Gregory R. Larkin. 2003. What Good Are Positive Emotions in Crises? A Prospective Study of Resilience and Emotions Following the Terrorist Attacks on the United States on 11 th, 2001. Journal of Personality and Social Psychology 84: 365-76. [CrossRef] [PubMed]

Fredrickson, Barbara L., Roberta A. Mancuso, Christine Branigan, and Michele M. Tugade. 2000. The Undoing Effect of Positive Emotions. Motivation and Emotion 24: 237-58. [CrossRef] [PubMed]

Gábová, Kristýna, Klára Maliňáková, and Peter Tavel. 2021. Associations of Self-Esteem with Different Aspects of Religiosity and Spirituality. Československá Psychologie 65: 73-85. [CrossRef]

Gailliot, Matthew T., Brandon J. Schmeichel, and Jon K. Maner. 2007. Differentiating the Effects of Self-Control and Self-Esteem on Reactions to Mortality Salience. Journal of Experimental Social Psychology 43: 894-901. [CrossRef]

Gallagher, Stephen, Alejandro Solano, and Mercedes Liporace. 2020. State, but Not Trait Gratitude is Associated with Cardiovascular Responses to Acute Psychological Stress. Physiology \& Behavior 221: 112896. [CrossRef]

Gebauer, Jochen E., Constantine Sedikides, and Wiebke Neberich. 2012. Religiosity, Social Self-Esteem, and Psychological Adjustment: On the Cross-Cultural Specificity of the Psychological Benefits of Religiosity. Psychological Science 23: 158-60. [CrossRef] [PubMed]

Gentile, Brittany, Shelly Grabe, Brenda Dolan-Pascoe, Jean M. Twenge, Brooke E. Wells, and Alissa Maitino. 2009. Gender Differences in Domain-Specific Self-Esteem: A Meta-Analysis. Review of General Psychology 13: 34-45. [CrossRef]

Ghaffari, Azadeh, and Ayşe Çiftçi. 2010. Religiosity and Self-Esteem of Muslim Immigrants to the United States: The Moderating Role of Perceived Discrimination. The International Journal for the Psychology of Religion 20: 14-25. [CrossRef]

Ghafoor, Hina, Stefan M. Schulz, and Humaira Mohsin. 2018. Does Religiosity Ameliorate the Negative Impact of ObsessiveCompulsive Disorder on Self-Esteem? Mental Health, Religion E Culture 21: 171-79. [CrossRef]

Ghorbani, Nima, Paul J. Watson, Shiva Geranmayepour, and Zhuo Chen. 2013. Analyzing the Spirituality of Muslim Experiential Religiousness: Relationships with Psychological Measures of Islamic Religiousness in Iran. Archiv Für Religionspsychologie/Archive for the Psychology of Religion 35: 233-58. [CrossRef]

Grant, Adam M., and Francesca Gino. 2010. A Little Thanks Goes a Long Way: Explaining Why Gratitude Expressions Motivate Prosocial Behavior. Journal of Personality and Social Psychology 98: 946-55. [CrossRef]

Greenway, A. Philip, Lisa C. Milne, and Veronica Clarke. 2003. Personality Variables, Self-Esteem and Depression and an Individual's Perception of God. Mental Health, Religion \& Culture 6: 45-58. [CrossRef] 
Grubbs, Joshua B., Joshua Wilt, Nicholas Stauner, Julie J. Exline, and Kenneth I. Pargament. 2016. Self, Struggle, and Soul: Linking Personality, Self-Concept, and Religious/Spiritual Struggle. Personality and Individual Differences 101: 144-52. [CrossRef]

Guse, Tharina, Francesca Vescovelli, and Sarah-Ann Croxford. 2019. Subjective Well-Being and Gratitude Among South African Adolescents: Exploring Gender and Cultural Differences. Youth \& Society 51: 591-615. [CrossRef]

Haidt, Jonathan. 2003. The Moral Emotions. In Handbook of Affective Sciences. Edited by Richard J. Davidson, Klaus R. Scherer and H. Hill Goldsmith. Series in Affective Science; New York: Oxford University Press, pp. 852-70.

Hayes, Andrew F. 2013. Methodology in the Social Sciences. Introduction to Mediation, Moderation, and Conditional Process Analysis: A Regression-Based Approach. New York: Guilford Press.

Hill, Terrence D., Amy M. Burdette, Mark Regnerus, and Ronald J. Angel. 2008. Religious Involvement and Attitudes Toward Parenting Among Low-Income Urban Women. Journal of Family Issues 29: 882-900. [CrossRef]

Homan, Kris, and Lisa Hosack. 2019. Gratitude and the Self: Amplifying the Good Within. Journal of Human Behavior in the Social Environment 29: 874-86. [CrossRef]

Homan, Kristin J., Brittany L. Sedlak, and Elizabeth A. Boyd. 2014. Gratitude Buffers the Adverse Effect of Viewing the Thin Ideal on Body Dissatisfaction. Body Image 11: 245-50. [CrossRef]

Jackson, Brenda R., and Cindy S. Bergeman. 2011. How Does Religiosity Enhance Well-Being? The Role of Perceived Control. Psychology of Religion and Spirituality 3: 149-61. [CrossRef]

James, Rochelle, Jennifer Thames, Mukul Bhalla, and John Cornwell. 2003. Relationship Among Adolescent Self-Esteem, Religiosity, and Perceived Family Support. Psi Chi Journal of Psychological Research 8: 157-62. [CrossRef]

Joshanloo, Mohsen, and Fatemeh Daemi. 2015. Self-esteem Mediates the Relationship between Spirituality and Subjective Well-being in Iran. International Journal of Psychology 50: 115-20. [CrossRef] [PubMed]

Jun, Won Hee, Jinhyang Yang, and Eun Ju Lee. 2018. The Mediating Effects of Social Support and a Grateful Disposition on the Relationship between Life Stress and Anger in Korean Nursing Students. Asian Nursing Research 12: 197-202. [CrossRef] [PubMed]

Kaczmarek, Lukasz D., Todd B. Kashdan, Dariusz Drążkowski, Jolanta Enko, Michał Kosakowski, Agata Szäefer, and Aleksandra Bujacz. 2015. Why Do People Prefer Gratitude Journaling over Gratitude Letters? The Influence of Individual Differences in Motivation and Personality on Web-Based Interventions. Personality and Individual Differences 75: 1-6. [CrossRef]

Kane, Davis K., G. E. Kawika Allen, Mason Ming, Timothy B. Smith, Aaron P. Jackson, Derek Griner, Elizabeth Cutrer-Párraga, and P. Scott Richards. 2021. Forgiveness and Gratitude as Mediators between Religious Commitment and Well-Being among Latter-Day Saint Polynesian Americans. Mental Health, Religion E Culture 24: 195-210. [CrossRef]

Kashdan, Todd B., Anjali Mishra, William E. Breen, and Jeffrey J. Froh. 2009. Gender Differences in Gratitude: Examining Appraisals, Narratives, the Willingness to Express Emotions, and Changes in Psychological Needs. Journal of Personality 77: 691-730. [CrossRef] [PubMed]

Kling, Kristen C., Janet Shibley Hyde, Carolin J. Showers, and Brenda N. Buswell. 1999. Gender Differences in Self-Esteem: A Meta-Analysis. Psychological Bulletin 125: 470-500. [CrossRef]

Kong, Feng, Kairong Yang, Wenjing Yan, and Xuewen Li. 2021. How Does Trait Gratitude Relate to Subjective Well-Being in Chinese Adolescents? The Mediating Role of Resilience and Social Support. Journal of Happiness Studies 22: 1611-22. [CrossRef]

Kong, Feng, Ke Ding, and Jinging Zhao. 2015. The Relationships Among Gratitude, Self-Esteem, Social Support and Life Satisfaction Among Undergraduate Students. Journal of Happiness Studies 16: 477-89. [CrossRef]

Kossakowska, Marlena, and Piotr Kwiatek. 2014. Polska adaptacja kwestionariusza do badania wdzięczności GQ-6. Przegląd Psychologiczny 57: 503-14.

Kraus, Rachel, Scott A. Desmond, and Zachary D. Palmer. 2015. Being Thankful: Examining the Relationship Between Young Adult Religiosity and Gratitude. Journal of Religion and Health 54: 1331-44. [CrossRef] [PubMed]

Krause, Neal. 1992. Stress, Religiosity, and Psychological Well-Being among Older Blacks. Journal of Aging and Health 4: 412-39. [CrossRef]

Krause, Neal. 1995. Religiosity and Self-Esteem among Older Adults. The Journals of Gerontology. Series B, Psychological Sciences and Social Sciences 50: 236-46. [CrossRef]

Krause, Neal. 2006. Gratitude Toward God, Stress, and Health in Late Life. Research on Aging 28: 163-83. [CrossRef]

Krause, Neal. 2012. Religious involvement, humility, and change in self-rated health over time. Journal of Psychology and Theology 40: 199-210. [CrossRef]

Krause, Neal, Robert A. Emmons, and Gail Ironson. 2015. Benevolent Images of God, Gratitude, and Physical Health Status. Journal of Religion and Health 54: 1503-19. [CrossRef]

Lambert, Nathaniel M., Frank D. Fincham, Scott R. Braithwaite, Steven M. Graham, and Steven R. H. Beach. 2009. Can Prayer Increase Gratitude. Psychology of Religion and Spirituality 1: 139-49. [CrossRef]

Lavelock, Caroline R., Brandon J. Griffin, Everett L. Worthington, Eric G. Benotsch, Yin Lin, Chelsea L. Greer, Rachel C. Garthe, Jennifer A. Coleman, Chelsea M. Hughes, Don E. Davis, and et al. 2016. A Qualitative Review and Integrative Model of Gratitude and Physical Health. Journal of Psychology and Theology 44: 55-86. [CrossRef]

Layous, Kristin, and Sonja Lyubomirsky. 2014. Benefits, Mechanisms, and New Directions for Teaching Gratitude to Children. Edited by Shannon Suldo. School Psychology Review 43: 153-59. [CrossRef]

Leary, Mark. 2003. Commentary on Self-Esteem as an Interpersonal Monitor: The Sociometer Hypothesis (1995). Psychological Inquiry 14: $270-74$. 
Leary, Mark R. 1999. Making Sense of Self-Esteem. Current Directions in Psychological Science 8: 32-35. [CrossRef]

Lin, Chih-Che. 2015a. Self-Esteem Mediates the Relationship between Dispositional Gratitude and Well-Being. Personality and Individual Differences 85: 145-48. [CrossRef]

Lin, Chih-Che. 2015b. Gratitude and Depression in Young Adults: The Mediating Role of Self-Esteem and Well-Being. Personality and Individual Differences 87: 30-34. [CrossRef]

Loi, Natasha M., and Di Helen Ng. 2021. The Relationship between Gratitude, Wellbeing, Spirituality, and Experiencing Meaningful Work. Psych 3: 85-95. [CrossRef]

Łaguna, Mariola, Kinga Lachowicz-Tabaczek, and Irena Dzwonkowska. 2007. Skala Samooceny SES Morrisa Rosenberga—Polska Adaptacja Metody. Psychologia Społeczna 2: 164-76.

Magyar-Russell, Gina. 2021. Introduction to the Special Issue: The Study of Religious and Spiritual Struggles: An Interdisciplinary Endeavor. Religions 12: 53. [CrossRef]

Markstrom, Carol A. 1999. Religious Involvement and Adolescent Psychosocial Development. Journal of Adolescence 22: 205-21. [CrossRef]

McCullough, Michael, Robert Emmons, and Jo-Ann Tsang. 2002. The Grateful Disposition: A Conceptual and Empirical Topography. Journal of Personality and Social Psychology 82: 112-27. [CrossRef]

McCullough, Michael E., Jo-Ann Tsang, and Robert A. Emmons. 2004. Gratitude in Intermediate Affective Terrain: Links of Grateful Moods to Individual Differences and Daily Emotional Experience. Journal of Personality and Social Psychology 86: 295-309. [CrossRef] [PubMed]

McCullough, Michael E., Shelley D. Kilpatrick, Robert A. Emmons, and David B. Larson. 2001. Is Gratitude a Moral Affect? Psychological Bulletin 127: 249-66. [CrossRef] [PubMed]

Mesurado, Belén, Santiago Resett, Mariana Tezón, and Claudia E. Vanney. 2021. Do Positive Emotions Make You More Prosocial? Direct and Indirect Effects of an Intervention Program on Prosociality in Colombian Adolescents During Social Isolation Due to COVID-19. Frontiers in Psychology 12: 3343. [CrossRef] [PubMed]

Newman, Jon S., and Kenneth I. Pargament. 1990. The Role of Religion in the Problem-Solving Process. Review of Religious Research 31: 390-404. [CrossRef]

Ng, Eddie Chi Wai, and Charles C. Chan. 2015. The Gratitude of Underprivileged Young People in Hong Kong: The Potential Role of Religious Mentors. Journal of Psychology and Theology 43: 140-47. [CrossRef]

O'Connell, Brenda H., and Mary Killeen-Byrt. 2018. Psychosocial Health Mediates the Gratitude-Physical Health Link. Psychology, Health \& Medicine 23: 1145-50. [CrossRef]

Orth, Ulrich, and Richard W. Robins. 2014. The Development of Self-Esteem. Current Directions in Psychological Science 23: 381-87. [CrossRef]

Park, Gewnhi, Charlotte van Oyen-Witvliet, Jorge A. Barraza, and Benjamin U. Marsh. 2021. The Benefit of Gratitude: Trait Gratitude is Associated with Effective Economic Decision-Making in the Ultimatum Game. Frontiers in Psychology 12: 1190. [CrossRef] [PubMed]

Petrocchi, Nicola, and Alessandro Couyoumdjian. 2016. The Impact of Gratitude on Depression and Anxiety: The Mediating Role of Criticizing, Attacking, and Reassuring the Self. Self and Identity 15: 191-205. [CrossRef]

Preś, Joanna E., Jacek Kurpisz, Justyna Pełka-Wysiecka, Katarzyna Adamowicz, Daria Suchecka-Fidura, Marta Ilnicka, Monika Mak, and Jerzy Samochowiec. 2020. What Regulates Gratitude Response of Women and Men? The Role of the Received Good, Psychosocial Factors, and Repayment. Psychological Reports 123: 395-419. [CrossRef]

Pyszczynski, Tom, Jeff Greenberg, Sheldon Solomon, Jamie Arndt, and Jeff Schimel. 2004. Why Do People Need Self-Esteem? A Theoretical and Empirical Review. Psychological Bulletin 130: 435-68. [CrossRef] [PubMed]

Rash, Joshua A., M. Kyle Matsuba, and Kenneth M. Prkachin. 2011. Gratitude and Well-Being: Who Benefits the Most from a Gratitude Intervention? Applied Psychology: Health and Well-Being 3: 350-69. [CrossRef]

Reckart, Hannah, E. Scott Huebner, Kimberly J. Hills, and Robert F. Valois. 2017. A Preliminary Study of the Origins of Early Adolescents' Gratitude Differences. Personality and Individual Differences 116: 44-50. [CrossRef]

Reiland, Sarah, and Dean Lauterbach. 2008. Effects of Trauma and Religiosity on Self-Esteem. Psychological Reports 102: 779-90. [CrossRef]

Rooney, Evan E., Benjamin Oosterhoff, and Julie B. Kaplow. 2020. Associations between Dimensions of Religiousness and Psychosocial Functioning among Bereaved Youth. Death Studies 44: 440-49. [CrossRef] [PubMed]

Rosenberg, Morris. 1965. Rosenberg Self-Esteem Scale. Princeton: Princeton University Press. [CrossRef]

Rosenberg, Morris, Carmi Schooler, Carrie Schoenbach, and Florence Rosenberg. 1995. Global Self-Esteem and Specific Self-Esteem: Different Concepts, Different Outcomes. American Sociological Review 60: 141-56. [CrossRef]

Rosmarin, D., Elizabeth J. Krumrei, and K. Pargament. 2010. Are Gratitude and Spirituality Protective Factors Against Psychopathology. International Journal of Existential Psychology \& Psychotherapy 3: 1-5.

Ryan, M. J. 2007. Giving Thanks: The Gifts of Gratitude. Newburyport: Conari Press.

Sandage, Steven J., Peter C. Hill, and Deanne C. Vaubel. 2011. Generativity, Relational Spirituality, Gratitude, and Mental Health: Relationships and Pathways. The International Journal for the Psychology of Religion 21: 1-16. [CrossRef] 
Sanders, Peter W., G. E. Kawika Allen, Lane Fischer, P. Scott Richards, David T. Morgan, and Richard W. Potts. 2015. Intrinsic Religiousness and Spirituality as Predictors of Mental Health and Positive Psychological Functioning in Latter-Day Saint Adolescents and Young Adults. Journal of Religion and Health 54: 871-87. [CrossRef] [PubMed]

Sansone, Randy A., and Lori A. Sansone. 2010. Gratitude and Well Being. Psychiatry 7: 18-22.

Schaefer, Jeanne A., and Rudolf H. Moos. 2001. Bereavement Experiences and Personal Growth. In Handbook of Bereavement Research: Consequences, Coping, and Care. Edited by Margaret S. Stroebe, Robert O. Hansson, Wolfgang Stroebe and Henk Schut. Washington, DC: American Psychological Association, pp. 145-67. [CrossRef]

Schieman, Scott, Alex Bierman, Laura Upenieks, and Christopher G. Ellison. 2017. Love Thy Self? How Belief in a Supportive God Shapes Self-Esteem. Review of Religious Research 59: 293-318. [CrossRef]

Sedikides, Constantine, and Jochen E. Gebauer. 2021. Do Religious People Self-Enhance? Current Opinion in Psychology 40: 29-33. [CrossRef] [PubMed]

Severiens, Sabine, and Geert ten Dam. 2011. Leaving College: A Gender Comparison in Male and Female-Dominated Programs. Research in Higher Education 53: 213-40. [CrossRef]

Smith, Christopher B., Andrew J. Weigert, and Darwin L. Thomas. 1979. Self-Esteem and Religiosity: An Analysis of Catholic Adolescents from Five Cultures. Journal for the Scientific Study of Religion 18: 51-60. [CrossRef]

Smith, Erin I., and Robert G. Crosby. 2017. Unpacking Religious Affiliation: Exploring Associations between Christian Children's Religious Cultural Context, God Image, and Self-Esteem across Development. The British Journal of Developmental Psychology 35: 76-90. [CrossRef] [PubMed]

Sowislo, Julia Friederike, and Ulrich Orth. 2013. Does Low Self-Esteem Predict Depression and Anxiety? A Meta-Analysis of Longitudinal Studies. Psychological Bulletin 139: 213-40. [CrossRef]

Stoeckel, Maggie, Carol Weissbrod, and Anthony Ahrens. 2015. The Adolescent Response to Parental Illness: The Influence of Dispositional Gratitude. Journal of Child and Family Studies 24: 1501-9. [CrossRef]

Świątek, Agata H., Małgorzata Szcześniak, and Grażyna Bielecka. 2021. Trait Anxiety and Social Media Fatigue: Fear of Missing Out as a Mediator. Psychology Research and Behavior Management 14: 1499-507. [CrossRef] [PubMed]

Szcześniak, Małgorzata. 2018. Indirect Reciprocity: The Concept and Psychological Mechanisms. Annals of Psychology 21: 107-29. [CrossRef]

Szcześniak, Małgorzata, and Celina Timoszyk-Tomczak. 2020. Religious Struggle and Life Satisfaction Among Adult Christians: Self-Esteem as a Mediator. Journal of Religion and Health 59: 2833-56. [CrossRef]

Szcześniak, Małgorzata, and Klaudia Strochalska. 2021. God's Perceived Engagement/Disengagement in Response to Prayer and Interpersonal Forgiveness: The Mediating Role of Positive Orientation. Religions 12: 846. [CrossRef]

Szcześniak, Małgorzata, Grażyna Bielecka, Iga Bajkowska, Anna Czaprowska, and Daria Madej. 2019. Religious/Spiritual Struggles and Life Satisfaction among Young Roman Catholics: The Mediating Role of Gratitude. Religions 10: 395. [CrossRef]

Szcześniak, Małgorzata, Wojciech Rodzeń, Agnieszka Malinowska, and Zdzisław Kroplewski. 2020a. Big Five Personality Traits and Gratitude: The Role of Emotional Intelligence. Psychology Research and Behavior Management 13: 977-88. [CrossRef] [PubMed]

Szcześniak, Małgorzata, Zdzisław Kroplewski, and Roman Szałachowski. 2020b. The Mediating Effect of Coping Strategies on Religious/Spiritual Struggles and Life Satisfaction. Religions 11: 195. [CrossRef]

Thompson, Maxine Seaborn, Melvin E. Thomas, and Rachel N. Head. 2012. Race, Socioeconomic Status, and Self-Esteem: The Impact of Religiosity. Sociological Spectrum 32: 385-405. [CrossRef]

Tulbure, Bogdan Tudor. 2015. Appreciating the Positive Protects Us from Negative Emotions: The Relationship between Gratitude, Depression and Religiosity. Procedia-Social and Behavioral Sciences 187: 475-80. [CrossRef]

Unanue, Wenceslao, Marcos Esteban Gomez Mella, Diego Alejandro Cortez, Diego Bravo, Claudio Araya-Véliz, Jesús Unanue, and Anja Van Den Broeck. 2019. The Reciprocal Relationship Between Gratitude and Life Satisfaction: Evidence From Two Longitudinal Field Studies. Frontiers in Psychology 10: 2480. [CrossRef]

Villani, Daniela, Angela Sorgente, Paola Iannello, and Alessandro Antonietti. 2019. The Role of Spirituality and Religiosity in Subjective Well-Being of Individuals With Different Religious Status. Frontiers in Psychology 10: 1-11. [CrossRef]

Voci, Alberto, Chiara A. Veneziani, and Giulia Fuochi. 2019. Relating Mindfulness, Heartfulness, and Psychological Well-Being: The Role of Self-Compassion and Gratitude. Mindfulness 10: 339-51. [CrossRef]

Waters, Lea, Sara B. Algoe, Jane Dutton, Robert Emmons, Barbara L. Fredrickson, Emily Heaphy, Judith T. Moskowitz, Kristin Neff, Ryan Niemiec, Cynthia Pury, and et al. 2021. Positive Psychology in a Pandemic: Buffering, Bolstering, and Building Mental Health. The Journal of Positive Psychology 2021: 1-21. [CrossRef]

Watkins, Philip C. 2014a. Conclusion: Explaining Gratitude. In Gratitude and the Good Life: Toward a Psychology of Appreciation. Edited by Philip C. Watkins. Dordrecht: Springer, pp. 241-53. [CrossRef]

Watkins, Philip C. 2014b. Does Gratitude Enhance Coping Ability? In Gratitude and the Good Life: Toward a Psychology of Appreciation. Edited by Philip C. Watkins. Dordrecht: Springer, pp. 159-74. [CrossRef]

Watson, Paul J., J. Trevor Milliron, Ronald J. Morris, and Ralph W. Hood. 1995. Religion and the Self as Text: Toward a Christian Translation of Self-Actualization. Journal of Psychology and Theology 23: 180-89. [CrossRef]

Watson, Paul J., Ralph W. Hood, Ronald J. Morris, and James R. Hall. 1985. Religiosity, Sin and Self-Esteem. Journal of Psychology and Theology 13: 116-28. [CrossRef] 
Wayment, Heidi A., Jack J. Bauer, and Kateryna Sylaska. 2015. The Quiet Ego Scale: Measuring the Compassionate Self-Identity. Journal of Happiness Studies 16: 999-1033. [CrossRef]

Wong, Y. Joel, Nicole T. Gabana, Nelson O. O. Zounlome, Nancy Goodrich Mitts, and Matthew Lucas. 2017. Cognitive Correlates of Gratitude among Prison Inmates. Personality and Individual Differences 107: 208-11. [CrossRef]

Wood, Alex M., John Maltby, Raphael Gillett, P. Alex Linley, and Stephen Joseph. 2008. The Role of Gratitude in the Development of Social Support, Stress, and Depression: Two Longitudinal Studies. Journal of Research in Personality 42: 854-71. [CrossRef]

Wood, Alex M., Stephen Joseph, and John Maltby. 2009. Gratitude Predicts Psychological Well-Being above the Big Five Facets. Personality and Individual Differences 46: 443-47. [CrossRef]

Yue, Xiao Dong, Neelam Arjan Hiranandani, Feng Jiang, Zhenhu Hou, and Xiaohua Chen. 2017. Unpacking the Gender Differences on Mental Health: The Effects of Optimism and Gratitude. Psychological Reports 120: 639-49. [CrossRef]

Zarzycka, Beata. 2014. The Internal Structure of the Polish Adaptation of the Religious Comfort and Strain Scale. Roczniki Psychologiczne/Annals of Psychology 17: 697-710.

Zarzycka, Beata, and Małgorzata M. Puchalska-Wasyl. 2019. Can Religious and Spiritual Struggle Enhance Well-Being? Exploring the Mediating Effects of Internal Dialogues. Journal of Religion and Health 59: 1897-912. [CrossRef] [PubMed]

Zeigler-Hill, Virgil, and Erin M. Myers. 2012. A Review of Gender Differences in Self-Esteem. In Psychology of Gender Differences. Edited by Sarah McGeown. Psychology Research Progress. Hauppauge: Nova Science Publishers, pp. 131-43.

Zhang, Lijuan, Shupeng Zhang, Ying Yang, and Caina Li. 2017. Attachment Orientations and Dispositional Gratitude: The Mediating Roles of Perceived Social Support and Self-Esteem. Personality and Individual Differences 114: 193-97. [CrossRef] 